\title{
Pain in the emergency department with one-week follow-up of pain resolution
}

\author{
C Celeste Johnston RN DEd ${ }^{1}$, Anita J Gagnon RN PhD ${ }^{1,2}$, Carolyn J Pepler RN PhD ${ }^{1}$, Patricia Bourgault RN MSc ${ }^{3}$
}

CC Johnston, AJ Gagnon, CJ Pepler, P Bourgault. Pain in the emergency department with one-week follow-up of pain resolution. Pain Res Manage 2005;10(2):67-70.

OBJECTIVES: To determine the intensity of pain in the emergency department (ED), the use of analgesics in relation to pain intensity, which patients are at risk for unresolved pain at one week postdischarge, and the postdischarge treatment of pain.

METHODS: Patients $(n=871)$ admitted to two urban, universityaffiliated EDs who were experiencing any pain were recruited on different shifts over the summer months of 1997. Pain intensity was self-reported, and chart reviews of the assessment, immediate treatment and follow-up prescriptions were conducted. Patients $(n=699)$ were contacted one week later, and reports of pain intensity, activity, resuming normal functions and patient attitudes toward pain were documented. Descriptive and regression analyses were performed on the results of patients with complete data $(n=585)$.

RESULTS: Mean pain intensity on admission was $6.0(\mathrm{SD}=2.5)$ on a zero to 10 visual analogue scale, and $5.0(\mathrm{SD}=2.9)$ at discharge $(n=871)$. One-quarter $(23 \%)$ of patients were given analgesics while in the ED; their mean pain intensity was 7.0 (95\% CI 6.7 to 7.3 ) versus 5.7 (95\% CI 5.5 to 5.9$)$ for those who were not given analgesics $(\mathrm{P}<0.001)$. At one week, the mean intensity for worst pain in the past $24 \mathrm{~h}$ was $5.2(\mathrm{SD}=2.9)$ and the usual pain intensity was $3.7(\mathrm{SD}=2.6)$. Using a cutoff point of pain greater than three on the zero to 10 visual analogue scale as residual pain at one week, 35\% $(n=207)$ remained in pain, with musculoskeletal pain accounting for half $(n=102)$ of those cases. Logistic regression showed that the following patients were most likely to have pain at one week: women; those with pain present longer than $48 \mathrm{~h}$ before ED visit; those with a high discharge pain rating; those who were taking analgesics; and those who had pain of musculoskeletal origin. Both the attitudes and beliefs about pain and the treatment of pain while in the ED or on discharge were unrelated to the presence of residual pain at one week. An examination of the same factors in relation to the return to normal activities found that they were similar, with the exception that admission and not discharge pain intensity was predictive of not returning to normal activities.

CONCLUSIONS: More than one-third of patients presenting to the ED with pain do not experience resolution of their pain. Women presenting with severe musculoskeletal pain of more than a week in duration are less likely to have resolution of their pain and to return to normal activities within a week of the ED visit.

Key Words: Analgesics; Emergency department; Factors predicting pain resolution; Pain; Pain resolution

\section{La douleur au département d'urgence avec suivi de la résolution de la douleur au bout d'une semaine}

OBJECTIFS : Déterminer l'intensité de la douleur au département d'urgence (DU), le recours aux analgésiques selon l'intensité de la douleur, les patients vulnérables à une douleur non résolue une semaine après le congé et le traitement de la douleur après le congé.

MÉTHODOLOGIE : Les patients $(\mathrm{n}=871)$ admis dans deux DU urbains affiliés à une université qui souffraient d'une douleur, quelle qu'elle soit, ont été recrutés à différents quarts de travail pendant l'été 1997. L'intensité de la douleur était auto-évaluée, et les dossiers ont été examinés pour connaitre l'évaluation, le traitement immédiat et les prescriptions de suivi. On a communiqué avec les patients $(\mathrm{n}=699)$ une semaine plus tard, et le compte rendu de l'intensité de la douleur, des activités à la reprise des fonctions normales et de l'attitude des patients envers la douleur ont été documentés. Des analyses descriptives et de régression ont été exécutées d'après les résultats des patients ayant fourni des données complètes $(\mathrm{n}=585)$.

RÉSULTATS : L'intensité moyenne de la douleur à l'admission était de $6,0($ ÉT $=2,5)$ selon une échelle analogique visuelle de zéro à 10, et de 5,0 (ÉT $=2,9)$ au congé $(\mathrm{n}=871)$. Le quart $(23 \%)$ des patients avaient reçu des analgésiques au DU, et l'intensité moyenne de la douleur était de 7,0 $(95 \% \mathrm{IC}=6,7$ à 7,3$)$ par rapport à $5,7(95 \% \mathrm{IC}=5,5$ à 5,9$)$ pour ceux qui n'avaient pas reçu d'analgésiques $(\mathrm{P}<0,001)$. Au bout d'une semaine, l'intensité moyenne de la pire douleur au cours de 24 heures précédentes était de 5,2 (ÉT=2,9) et l'intensité habituelle de la douleur, de 3,7 $($ ÉT $=2,6)$. Selon un seuil limite de la douleur supérieur à trois sur l'échelle analogique visuelle de zéro à 10 correspondant à une douleur résiduelle au bout d'une semaine, $35 \%(\mathrm{n}=207)$ continuaient à éprouver de la douleur, les douleurs musculosquelettiques représentant la moitié $(n=102)$ de ces cas. La régression logistique a démontré que les patients suivants étaient plus susceptibles d'éprouver de la douleur au bout d'une semaine : les femmes, ceux qui éprouvaient de la douleur depuis plus de $48 \mathrm{~h}$ avant leur visite au DU, ceux dont l'évaluation de la douleur était élevée au congé, ceux qui prenaient des analgésiques et ceux qui éprouvaient des douleurs d'origine musculosquelettique. Ni les attitudes et les convictions au sujet de la douleur, ni le traitement de la douleur au DU ou au congé n'étaient reliés à la présence de douleur résiduelle au bout d'une semaine. Un examen des mêmes facteurs par rapport au retour aux activités normales a permis d'établir qu'ils étaient similaires, à l'exception du fait que c'était l'intensité de la douleur à l'admission, plutôt qu'au congé, qui était prédictif de la non-reprise des activités normales.

CONCLUSIONS : Plus du tiers des patients qui se rendent au DU en raison de douleurs ne bénéficient pas d'une résolution de ces douleurs. Les femmes souffrant de graves douleurs musculosquelettiques depuis plus d'une semaine sont moins susceptibles de voir leur douleur se résoudre et de reprendre leurs activités normales dans la semaine suivant leur visite au DU.

\footnotetext{
${ }^{1}$ McGill University School of Nursing; ${ }^{2}$ Department of Obstetrics and Gynecology, McGill University School of Nursing, Montreal; ${ }^{3}$ Centre
} hospitalier de l'université de Sherbrooke, Sherbrooke, Quebec

Correspondence: Dr Celeste Johnston, McGill University School of Nursing, 3506 University Street, Montreal, Quebec H3A 2 A7.

Telephone 514-398-4157, fax 514-398-8455, e-mail celeste.johnston@mcgill.ca 
$\mathrm{G}$ iven reports that approximately three-quarters of patients in the emergency department (ED) experience pain $(1,2)$, it would be appropriate to identify pain as a major issue in that setting. Despite this figure, there have been reports of 'oligoanalgesia' in the ED for more than a decade (3). One earlier study (3) consisted of a chart review of 198 patients presenting sequentially over a two-month period to the ED with noncritical but acutely painful surgical or medical conditions; $56 \%$ received no analgesia. Of those who received analgesia, $42 \%$ waited $2 \mathrm{~h}$ before administration and 32\% received inadequate doses. More recently, other studies have suggested that poor analgesic management of pain in the ED remains common $(1,4-7)$. Ducharme and Barber (8) and Ngai and Ducharme (9) found that even patients with severe pain scores were not adequately treated. A recent review suggested that the problem of undertreatment of pain in the ED is multifactorial and that staff bias regarding drug-seeking behaviours or addiction contributed largely to the problem (10).

There are certain patient factors that may be associated with the treatment of pain. While sex may be a factor in receiving analgesia (eg, women have been perceived as having more pain and, thus, received more analgesia [11]), one recent report investigating factors associated with patients' self-report of clinically important pain found no differences between male and female patients (12). This study (12) also found no differences in incidence of important pain in relation to age or source of pain; these findings reflect similar results found by Lewis et al (4). The ethnicity of the patient has also been reported to be a significant factor (13). The authors in the present study went beyond the observation of observed ethnic differences in patients being offered analgesics by presenting cases to the staff while blinding the ethnicity of the patients. As a result, the differential disappeared, thus validating the observed discrimination.

Other than a Swiss report following whiplash injury patients from the ED (14), the authors found no other reports of patients followed beyond discharge that investigated whether the pain they presented with in the ED had disappeared. It is important to know if there is any relationship between the resolution of pain and ED practices, or if medical or demographic factors are more predictive of pain resolution in the ED. The purpose of the present study was to identify potential factors related to unresolved pain one week following a visit to the ED.

\section{SAMPLE}

During the summer months of 1997 (for current data comparison, see "Recent validation" section below), all triaged patients with any pain other than chest pain, who could communicate in English or French, who were not social (eg, conjugal violence or wandering homeless cases) or psychiatric or in a lifethreatening state, and who agreed to be approached regarding the study had the study explained to them and were given a printed description of the study and a consent form. Nine hundred fifty-nine subjects were approached, of which 890 consented to participate (93\%). Data were collected at admission from 871 patients. Of those 871 , contact was made one week following the ED visit with 699 patients (80\%). Complete data, however, were obtained from 585 patients.

\section{METHODS}

The protocol and consent forms were approved for ethical consideration by the university medical Internal Review Board, which reviews protocols at multiple sites. Sampling in two urban, university-based
TABLE 1

Sample patient characteristics

\begin{tabular}{lcc}
\hline & $\begin{array}{c}\text { Patients presenting } \\
\text { in the ED (n=871) }\end{array}$ & $\begin{array}{c}\text { Patients followed-up } \\
\text { at one week (n=699) }\end{array}$ \\
\hline Age, mean (SD) & $44.1(18.3)$ & $43.6(17.9)$ \\
Sex (\% male) & 44 & 43 \\
Sick leave available (\%) & 33 & 34 \\
Acute (\% less than one week) & 74 & 75 \\
Analgesics given in ED & 22.5 & 22.8 \\
Analgesics prescribed & 36.2 & 35.6 \\
at discharge & & \\
\hline
\end{tabular}

ED Emergency department

hospital EDs took place over an eight-week period during the summer months of 1997. Each week, the following periods were covered: one weekday night shift; one weekend day and evening shift; and all weekday periods from 08:00 to 22:00. Weekend nights were sampled twice during the eight-week period. The sampling times were designed to reflect the usual volume of patient flow. The triage nurse screened for the presence of pain and the level and type of acuity of pain, and determined eligibility. Eligible patients were asked if they would be willing to hear about a study on pain in the ED. These patients' charts were tagged, and the patients were approached for consent to participate in the study.

On enrollment, patients were asked for a brief history of their present pain, the intensity of their present pain on a numerical scale of zero to 10 , and some sociodemographic information. Patients also completed a questionnaire on their beliefs about pain. This questionnaire, originally developed for cancer patients, tests attitudes about analgesics and pain (15). It has eight statements (such as "pain medication should only be taken when pain is severe") that are rated on a zero to 10 numerical scale of agreement. For the purposes of the present study, the original questions were edited by changing "cancer pain" to "pain".

As patients were discharged from the ED, they were asked to rate their pain intensity and reminded that they would be contacted by telephone in one week. The medical record was reviewed for any documentation related to their pain, any prescribed or administered analgesics, and discharge orders. When the patients were recontacted at one week, they were asked about any medications they had taken, any treatments they had sought or self-administered, whether they had resumed their normal activities, and to rate their worst and usual pain intensity over the past $24 \mathrm{~h}$.

\section{RESULTS}

Of the 871 patients enrolled at the time of the ED visit, 699 were successfully contacted one week later. Of the patients not followed, 41 were admitted, 12 withdrew, and the remaining 119 were not found, despite having second telephone contacts for many of them. Descriptive information about patients at the ED visit and during follow-up is presented in Table 1. Pain intensity levels are shown in Figure 1. Not all patients answered all questions, but numbers are reported when they are less than the total sample.

Approximately one-half of the patients (446/861 or $51.8 \%$ ) reported that the onset of pain was sudden, that is, within $48 \mathrm{~h}$. Only 2\% $(n=41)$ had pain that had been present longer than three months. Almost one-half of the patients (366/829 or $44 \%$ reporting) had taken analgesics before coming to the ED.

Pain was documented as a symptom in $82 \%$ of cases, with both the nurse and the doctor documenting on $62 \%$ of the patients, nurses alone in $30 \%$ and doctors alone in $8 \%$; however, intensity of pain was documented for only $28 \%$ of patients, with doctors 
accounting for one-half of those, nurses for one-third, and both nurses and doctors for the remainder. During the time the patients were in the $\mathrm{ED}$, only $23 \%(\mathrm{n}=196)$ received analgesia, in spite of over $80 \%$ with documented pain. The patients who did receive analgesia had higher pain intensities (mean 7.0, versus 5.7 for those who did not receive analgesia). Of the patients who reported pain, 235 reported severe pain intensity of 8/10 or greater. While these patients were more likely to receive analgesia of any kind $\left(\chi^{2}[1]=20.811, P<0.0001\right)$, including narcotic analgesia $\left(\chi^{2}[1]=30.900, P<0.0001\right)$, only $28.5 \%$ of them received narcotic analgesia. Despite this, the mean change in pain score from admission to discharge was almost one point (0.969), which is considered of minimal clinical importance (16), although 16\% reported worse pain at discharge and $43 \%$ remained unchanged. Approximately onethird (315 or $36 \%)$ received a prescription for analgesics on discharge, which was more than the number that had received analgesics while in the ED.

Pain attitudes were measured on a zero to 10 Likert-type scale, and six of the eight statements had neutral mean agreement scores of between 2.8 and 4.2. However, two statements had higher mean scores of greater than seven, meaning that there was agreement with the statement. These two statements were, "Pain medicine cannot really control pain" and "Complaints of pain could distract my physician from treating my underlying illness". The statements were added to form a total pain attitude scale which was not significantly related to any demographic or medical variables.

At one-week follow-up, patients were asked about their current pain intensity and interference over the past $24 \mathrm{~h}$, as well as what treatments they had taken or consultations they had sought. More than one-third (36\%) reported still having problems, and $38 \%$ had not resumed normal activities. Following descriptive analyses, factors that were considered prime predictors of unresolved pain - age, sex, diagnostic category, duration of pain, pain intensity on admission, pain intensity on discharge, receipt of analgesia in $\mathrm{ED}$, prescription of analgesic at discharge from ED, whether they had taken analgesics during the week, availability of sick leave and pain attitudes - were entered into two binary logistic regressions, one on pain resolution and one on the resumption of daily activities (Table 2). The factors that predicted residual pain of greater than three on a scale of zero to 10 at one week were being female, having pain of musculoskeletal origin, having higher pain on discharge, having pain for more than $48 \mathrm{~h}$ before presenting to the $\mathrm{ED}$ and still taking analgesics. The factors that predicted nonresumption of usual activities were similar except that severe pain on admission (as opposed to discharge) predicted nonresumption of usual activities, and the duration of pain before presenting in the ED was not significant. Women were no less likely to have received analgesics in the ED

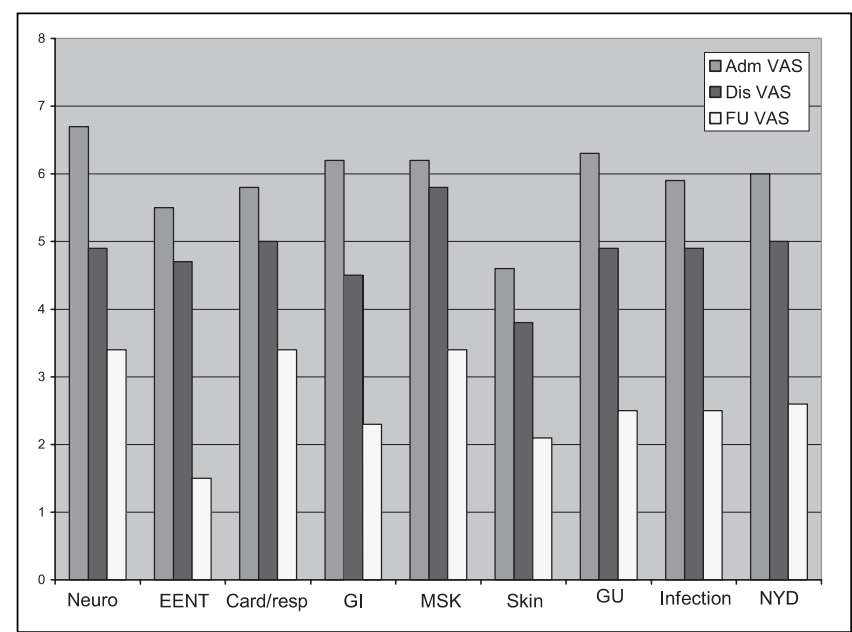

Figure 1) Pain scores by diagnostic category on admission (Adm), at discharge (Dis), and at one-week follow-up (FU) ( $n=871$ at Adm, $n=722$ at Dis, $n=695$ at FU). EENT Eye, ear, nose, throat; Card/resp Cardiac and/or respiratory; GI Gastrointestinal; GU Genitourinary; MSK Musculoskeletal; Neuro Neurological; NYD Not yet diagnosed; VAS Visual analogue scale

( $24 \%$, versus $22 \%$ for men) or to not be prescribed analgesics ( $33 \%$, versus $35 \%$ for men), although they were more likely ( $60 \%$, versus $39 \%$ for men) to have taken analgesics in the week following the ED visit $\left(\chi^{2}[1]=7.490, P<0.004\right)$.

\section{Recent validation}

In August 2003, patients meeting similar criteria were recruited over two $24 \mathrm{~h}$ periods in one of the two original participating EDs. Sixty patients were enrolled, and data on presenting pain intensity, documentation of pain, and analgesics administered and prescribed were collected. The pain intensity on admission was 5.9, which was identical to the initial study. Pain was documented in $88 \%$ of patients, with intensity noted in $35 \%-$ very close to the observations in the first group $(82 \%$ and $28 \%$, respectively). Analgesics were administered to an increased number ( $45 \%$, versus $23 \%$ in the initial study), but the same percentage ( $35 \%$, versus $36 \%$ in the initial study) were prescribed analgesics on discharge.

\section{DISCUSSION}

Similar to other reports of pain in the ED, the present study reflects low analgesic administration to patients during their $\mathrm{ED}$ visit. While this lack of treatment may be considered deplorable on moral grounds, it does not appear to predict outcome after one week more than other factors such as sex or the history and intensity of the pain. The predictive factors are not within the

\section{TABLE 2}

Significant factors from logistic regression of unresolved pain and nonresumption of usual activities

\begin{tabular}{|c|c|c|c|c|}
\hline & $\begin{array}{l}\text { Unresolved pain } \\
\text { OR }(95 \% \mathrm{Cl})\end{array}$ & $\mathbf{P}$ & $\begin{array}{c}\text { Nonresumption of } \\
\text { usual activities OR }(95 \% \mathrm{Cl})\end{array}$ & $\mathbf{P}$ \\
\hline Sex (being female) & $1.518(1.027-2.244)$ & 0.036 & $1.627(1.090-2.429)$ & 0.017 \\
\hline Admission pain severe (8-10 on VAS) & $2.236(0.835-3.385)$ & 0.135 & $2.158(1.066-4.369)$ & 0.003 \\
\hline Duration of $48 \mathrm{~h}$ or more & $1.795(1.222-2.366)$ & 0.002 & $1.184(0.801-1.750)$ & 0.398 \\
\hline Musculoskeletal diagnosis & $2.097(1.377-3.019)$ & 0.001 & $3.008(1.963-4.608)$ & 0.00001 \\
\hline Taking analgesics post-ED visit & $1.834(1.215-2.769)$ & 0.004 & $3.155(2.078-4.789)$ & 0.00001 \\
\hline
\end{tabular}

ED Emergency department; VAS Visual analogue scale 
control of ED practice; however, the present study should alert staff in the ED to patients who may be at risk for unresolved pain. Patients with a long history of pain may be viewed as drug seeking and, thus, not adequately medicated (10), although it could more simply be that chronic pain is prevalent and difficult to treat (17). It is interesting that patients with pain longer than $48 \mathrm{~h}$ were more likely to have pain a week later, but this did not predict whether they had resumed normal activities. It could be that some patients who have had pain for a longer period of time have learned how to resume normal activities in spite of their unresolved pain. On the other hand, it could be that their standard for what constitutes normal activities has become modified due to the longer duration of the pain. Patients with high levels of pain in the ED were more likely to receive analgesics both in the ED and after discharge; however, the analgesics do not appear to be effective in controlling the pain.

Being female predicted both nonresolution of pain and nonresumption of normal activities. The effect of sex on pain has been a subject of extensive review $(18,19)$, the findings of which are consistent with the results from the present study. In the present study, there were no differences in the treatment of pain between men and women, as has been reported elsewhere (20).

The documentation of pain in $82 \%$ of patients (all of whom had pain) is encouraging; however, the level of analgesia administration remains low, particularly in patients with severe pain. Interestingly, more patients were given prescriptions for analgesics at discharge than while they were actually in the ED. Presumably, this is related to patient flow in the ED and the desire on the part of staff to discharge patients as soon as possible.

The attitudes toward pain did not seem to be related to any other variables. It was nevertheless interesting that there was a general belief that analgesics could not control pain very well and that complaining of pain to doctors distracted from the treatment of the underlying illness. Belief in pain medication being ineffective was not related to whether the patient had taken analgesics before the ED visit nor to analgesic consumption during the week after the ED visit. This puts into question the relationship between attitudes and behaviour.

There are some methodological issues that need to be considered when interpreting the results of the present study. We did not sample $24 \mathrm{~h}$ /day for all days of the week; therefore, actual prevalence of pain in the ED cannot be determined. We specifically only recruited patients who presented with pain; as a result, we could have missed patients discharged with pain who initially did not present with pain (eg, patients who underwent painful diagnostic procedures). While there appeared to be a high participation rate, this figure is probably inflated because patients who refused the triage nurse's invitation to be approached about the study were not accounted for in determining the refusal rate because that information proved to be impossible to obtain. Therefore, there is a bias in the sampling that could have led to inflation of the amount of pain patients were experiencing, assuming that those with more pain would be more interested in talking to someone about their pain. The influence of the bias is, however, unknown. Future studies should include more information on patients refusing to participate in a study.

The recent observations that were made indicate that there might be some changes in practice. There was a slight increase in the documentation of pain intensity levels (from 28\% to $35 \%)$. More importantly, there was an increase in analgesic administration from $23 \%$ to $45 \%$. Because the large data set showed no relationship between analgesic administration in the ED and subsequent pain resolution, this may not be important in the longer term, but is certainly important in terms of immediate attention to pain. There was no indication of change in analgesia prescription rates at discharge, which would be more likely to affect the one-week status of the pain. It would be enlightening to replicate the original study in EDs and instead treat pain aggressively both in the ED and on discharge to determine if pain management interacts with intrinsic patient factors such as sex and duration of pain, or whether aggressive pain management alone could override those factors.

ACKNOWLEDGEMENTS: This study was supported by a grant from the Canadian Institutes of Health Research, and by personal support to CJ from the National Health Research and Development Program and to AG from the Fonds de Recherche en Santé du Québec. The authors wish to thank Dr Jim Ducharme for consultation on the study design, the students for collecting the data, and the staff of the emergency departments of the McGill University Health Centre, Montreal General and Royal Victoria sites (Montreal, Quebec).

\section{REFERENCES}

1. Tanabe P, Buschmann M. A prospective study of ED pain management practices and the patient's perspective. J Emerg Nurs 1999;25:171-7.

2. Tcherny-Lessenot S, Karwowski-Soulie F, Lamarche-Vadel A, Ginsburg C, Brunet F, Vidal-Trecan G. Management and relief of pain in an emergency department from the adult patients' perspective. J Pain Symptom Manage 2003;25:539-46.

3. Wilson JE, Pendleton JM. Oligoanalgesia in the emergency department. Am J Emerg Med 1989;7:620-3.

4. Lewis LM, Lasater LC, Brooks CB. Are emergency physicians too stingy with analgesics? South Med J 1994;87:7-9.

5. Morgan-Jones R. Pre-operative analgesia after injury. Injury 1996;27:539-41.

6. Petrack EM, Christopher NC, Kriwinsky J. Pain management in the emergency department: Patterns of analgesic utilization. Pediatrics 1997;99:711-4.

7. Guru V, Dubinsky I. The patient vs. caregiver perception of acute pain in the emergency department. J Emerg Med 2000;18:7-12.

8. Ducharme J, Barber C. A prospective blinded study on emergency pain assessment and therapy. J Emerg Med 1995;38:571-5.

9. Ngai B, Ducharme J. Documented use of analgesics in the emergency department and upon release of patients with extremity fractures. Acad Emerg Med 1997;4:1176-8.

10. Rupp T, Delaney KA. Inadequate analgesia in emergency medicine. Ann Emerg Med 2004;43:494-503.

11. Raftery KA, Smith-Coggins R, Chen AH. Gender-associated differences in emergency department pain management. Ann Emerg Med 1995;26:414-21.

12. Kelly AM. Does the clinically significant difference in visual analog scale pain scores vary with gender, age, or cause of pain? Acad Emerg Med 1998;5:1086-90.

13. Todd KH, Deaton C, D'Adamo AP, Goe L. Ethnicity and analgesic practice. Ann Emerg Med 2000;35:11-6.

14. Radanov BP, Sturzenegger M, Di Stefano G, Schnidrig A, Aljinovic M. Factors influencing recovery from headache after common whiplash. BMJ 1993;307:652-5.

15. Ward SE, Goldberg N, Miller-McCauley V, et al. Patient-related barriers to management of cancer pain. Pain 1993;52:319-24.

16. Powell CV, Kelly AM, Williams A. Determining the minimum clinically significant difference in visual analog pain score for children. Ann Emerg Med 2001;37:28-31.

17. Moulin DE, Clark AJ, Speechley M, Morley-Forster PK. Chronic pain in Canada - prevalence, treatment, impact and the role of opioid analgesia. Pain Res Manag 2002;7:179-84.

18. Fillingim RB. Sex, gender, and pain: Women and men really are different. Curr Rev Pain 2000;4:24-30.

19. Jones A, Zachariae R. Gender, anxiety, and experimental pain sensitivity: An overview. J Am Med Womens Assoc 2002;57:91-4.

20. Raftery KA, Smith-Coggins R, Chen AH. Gender-associated differences in emergency department pain management. Ann Emerg Med 1995;26:414-21. 


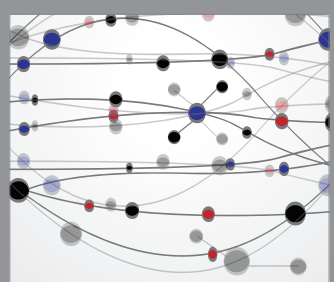

The Scientific World Journal
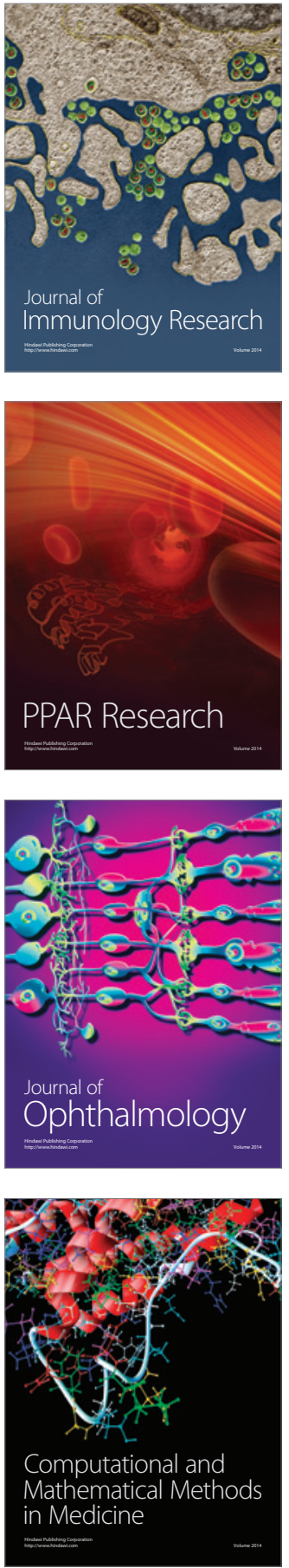

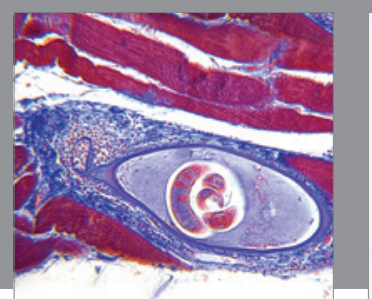

Gastroenterology Research and Practice

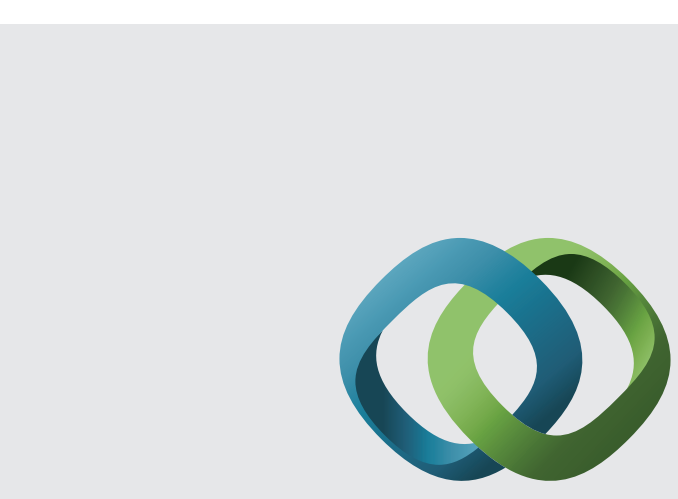

\section{Hindawi}

Submit your manuscripts at

http://www.hindawi.com
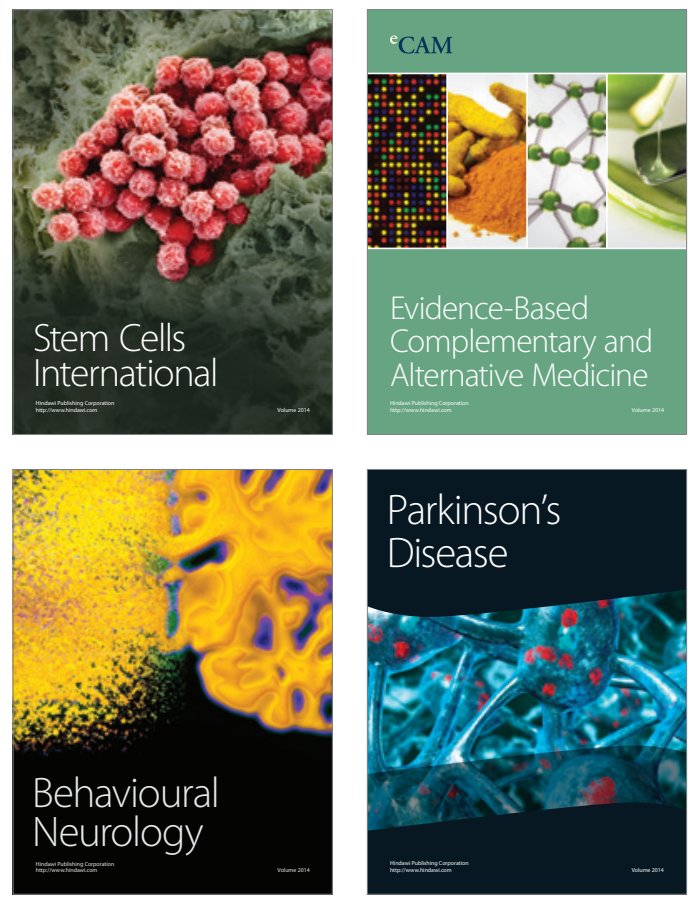
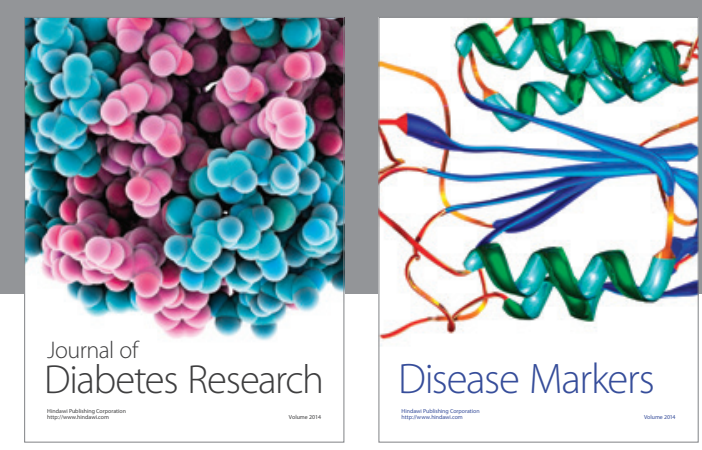

Disease Markers
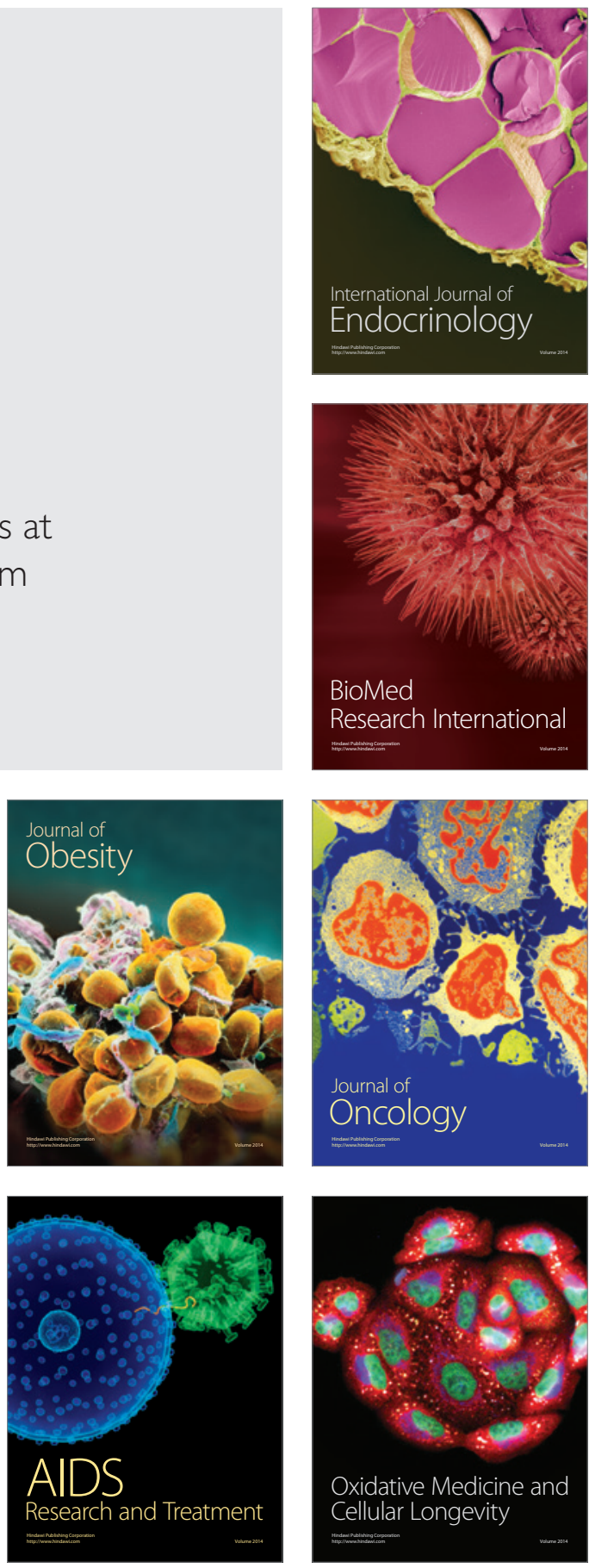